\title{
Neural Control of Heart Rate: a Comparison between Puppies and Adult Animals
}

\author{
SHARON E. MACE ${ }^{(50)}$ AND MATTHEW N. LEVY \\ Division of Investigative Medicine, The Mt. Sinai Medical Center, and Case Western Reserve University, Cleveland, \\ Ohio, USA
}

\section{Summary}

The heart rate responses to stimulation of the right and left cardiac autonomic nerves were evaluated in 20 puppies and 17 adult dogs. In every puppy and adult dog, the changes in heart rate were much greater with right- than with left-sided stimulation of the vagal or sympathetic nerves. At maximal stimulation frequencies, the \% changes in heart rate (mean \pm S.E.M.) were: right stellate, adults $+50.0( \pm 5.1)$ and puppies $+23.6( \pm 2.8)$; left stellate, adults $+20.0( \pm 2.4)$ and puppies $+5.6( \pm 2.3)$; right vagus, adults $-74.0( \pm 5.2)$ and puppies $-43.6( \pm 3.3)$; and left vagus, adults $\mathbf{- 4 4 . 1}( \pm 2.0)$ and puppies $-24.9( \pm 2.3)$. At any given stimulation frequency, the heart rate responses were significantly greater in adult dogs than in puppies, with either stellate or vagal stimulation. In $47 \%$ of the puppies and in $11 \%$ of the adult dogs, left stellate stimulation had no detectable effect on heart rate, although there was evidence of an increase in blood pressure in each of these animals. In these animals, fibers from the left stellate ganglion did not innervate the sinoatrial node.

Cardiac function in newborns and young animals is different from adults $(2,7,20,47,48)$. Biochemical and histologic studies suggest that the sympathetic innervation of the heart is anatomically incomplete in newborns $(18,27,33,42)$, whereas the parasympathetic innervation appears to be anatomically complete ( 8 , $12,15,17,44)$. The functional status of these autonomic nervous pathways in young animals has not been fully established, however. In the present investigation, we have evaluated functionally the chronotropic responses to autonomic stimulation in puppies. Also, we have compared the chronotropic responses to right- and left-sided autonomic stimulation in puppies and adult dogs.

\section{MATERIALS AND METHODS}

Twenty puppies from six litters and 17 adult dogs were anesthetized with sodium pentobarbital $(30 \mathrm{mg} / \mathrm{kg}$, intravenously or intraperitoneally). A tracheal cannula was inserted in each animal, and intermittent positive pressure respiration was instituted. The chest was opened transversely at the fourth intercostal space. Both stellate ganglia in the chest and both cervical vagi were isolated. Crushing the vagi and the rami communicantes to the stellate ganglia by means of tight ligatures eliminated the tonic neural activity to the heart $(1,26)$.

The atrial electrogram was recorded from a bipolar electrode catheter, which was introduced into the right atrial cavity. The atrial electrogram, arterial blood pressure (Statham PB23A transducer), and the heart rate were recorded on an eight-channel oscillograph (Brush, Mark 200). The heart rate was derived from the atrial electrogram with an analog computer (EAI-580).

Bipolar iridium electrodes were connected to a Grass S4 stimulator (with an isolation unit), in order to stimulate both stellate ganglia and the cardiac segments of both vagi. To prevent drying and to decrease current spread, mineral oil was applied to the cardiac nerves in the region of the stimulating electrodes. Stimuli to the stellate ganglia or vagus nerves were delivered at a supramaximal voltage $(10-15 \mathrm{~V})$, with a pulse width of $2 \mathrm{~ms}$, and at various constant frequencies. Responses were expressed as \% change from the heart rate that prevailed in the absence of nerve stimulation. The mean value at each stimulation frequency was obtained from the adult dogs and for the puppies. From this, second degree polynomial regression equations were derived for the heart rate responses as a function of the frequency of nerve stimulation $(21,38,39)$. The statistical significance of the data was determined by the analysis of variance $(19,21,38,39)$. This experimental design allows us to determine the simultaneous effects of various stimulation frequencies (both stellate and vagal), the side of stimulation (right versus left vagi or stellate nerves), and the age (adult dogs versus puppies; and to assess the extent of any interactions between these factors $(19,21,38,39)$. Puppies were divided into two groups based on age. Group I (10 puppies) were in the first month of life. Group II (10 puppies) were in the second month of life. The chronotropic responses to neural stimulation for puppies in the first month of life were compared with those for puppies in the second month of life. There were no statistically significant differences, so the data from puppies in both age groups were combined.

\section{RESULTS}

After interruption of the autonomic nerves to the heart, the mean heart rate of the adult dogs in the absence of neural stimulation was $130 \pm 6$ (S.E.M.) beats/min, and that of puppies was $139 \pm 7$ beats/min; the difference was not statistically significant. The $\%$ changes in heart rate as a function of the stimulation frequency are plotted in Figures 1 and 2.

Parasympathetic stimulation. In the adult dogs and in the puppies, the heart rate decreased as the frequency of vagal stimulation was increased. In the adult dogs, the plateau of chronotropic response was not reached until the frequency was raised to about $20-30 \mathrm{~Hz}$, whereas in the puppies, the plateau was reached at a much lower frequency, about $8-15 \mathrm{~Hz}$. The negative chronotropic effects of right vagal stimulation were about twice as great $(P<$ 0.001 ) as for left-sided stimulation in the adult dogs (Fig. 1; Tables 1 and 3). Likewise, in the puppies, the chronotropic effects of right vagal stimulation were about twice $(P<0.001)$ those for left-sided stimulation.

At any given stimulation frequency, the chronotropic effect in the puppies was less than in the adults. The maximum chronotropic responses in the puppies were about two-thirds $(P<0.001)$ of those in the adult animals (Fig. 1; Tables 1 and 3).

Sympathetic Stimulation. The heart rate increased as the frequency of stellate stimulation was raised, in both adult dogs and puppies. The chronotropic response in adult dogs and in puppies reached a plateau at about $5-10 \mathrm{~Hz}$. In puppies and adult dogs, the heart rate increments with right stellate stimulation were more than double $(P<0.001)$ those obtained with left stellate stimulation (Fig. 2; Tables 2 and 3).

In $47 \%$ of the puppies and in $11 \%$ of the adult dogs, there was 


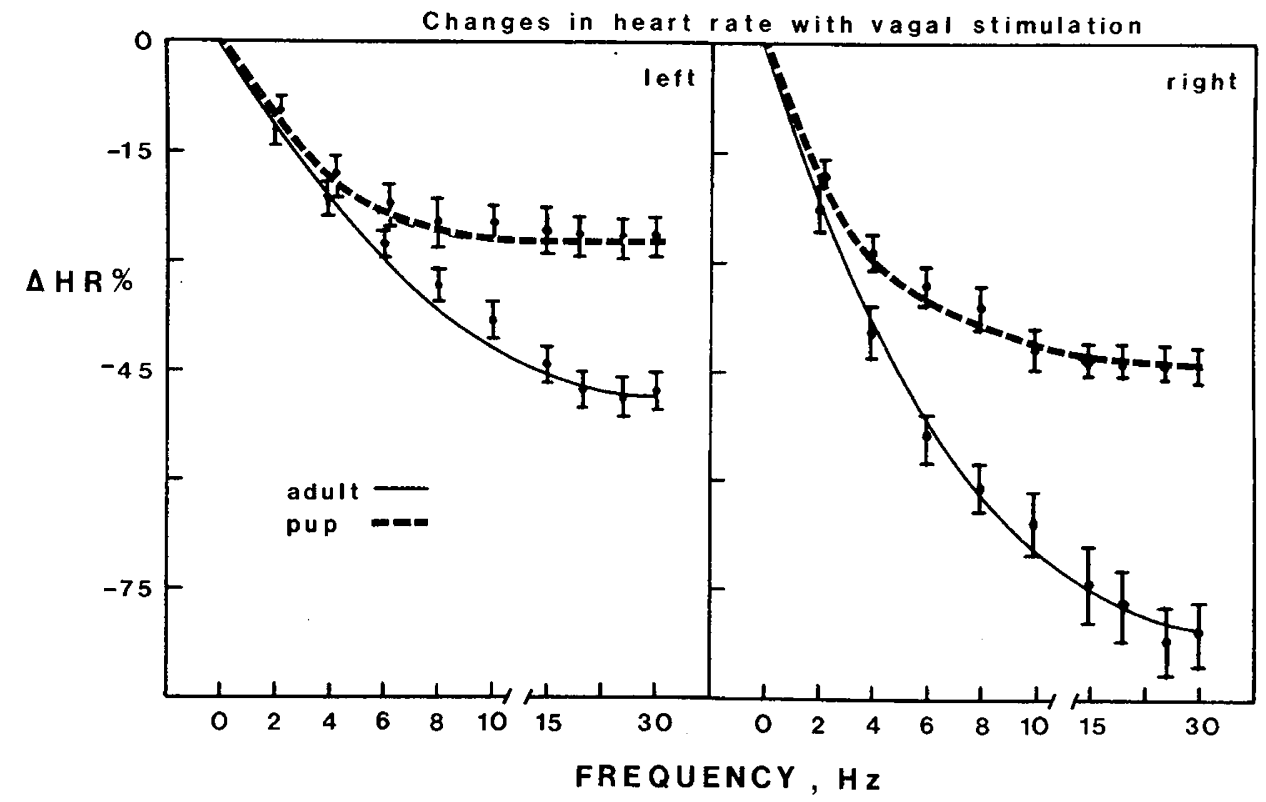

Fig. 1. Changes in heart rate as a function of the vagal stimulation frequency in adult dogs and in puppies. The right half is the mean change in heart rate \pm S.E.M. with right vagal stimulation. The left half is the mean change in heart rate \pm S.E.M. with left vagal stimulation. The regression equations for the curves are $\left(r\right.$ is the correlation coefficient): right vagus adult dogs, $\mathrm{y}=0.011 \mathrm{x}^{2}-0.769 \mathrm{x}+14.99(r=0.95)$ and puppies, $\mathrm{y}=0.053 \mathrm{x}^{2}-2.626 \mathrm{x}$ $+33.59(r=0.78)$; left vagus adult dogs, $\mathrm{y}=0.024 \mathrm{x}^{2}-0.889 \mathrm{x}+10.54(r=0.91)$ and puppies, $\mathrm{y}=0.276 \mathrm{x}^{2}-9.177 \mathrm{x}+73.12(r=0.68)$.

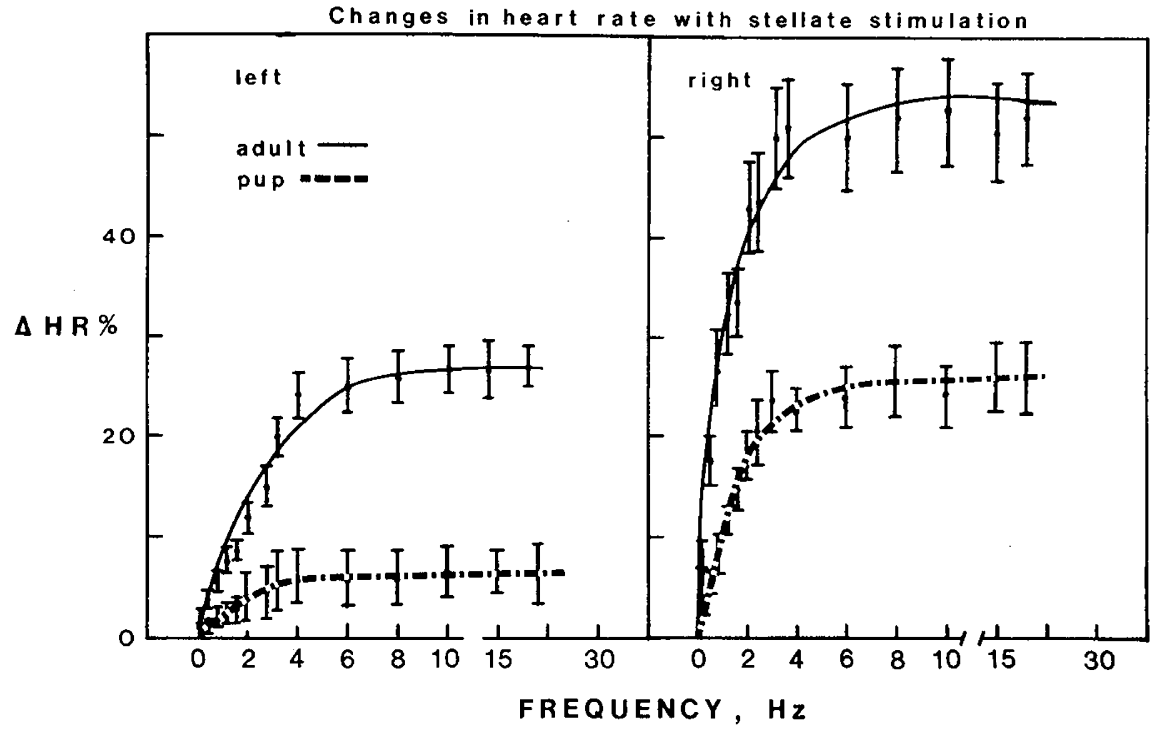

Fig. 2. Changes in heart rate as a function of the stellate stimulation frequency in adult dogs and in puppies. The right half is the mean change in heart rate \pm S.E.M. with right stellate stimulation. The left half is the mean change in heart rate \pm S.E.M. with left stellate stimulation. The regression equations for the curves are $\left(r\right.$ is the correlation coefficient): right stellate adult dogs, $\mathrm{y}=0.012 \mathrm{x}^{2}-0.505 \mathrm{x}+4.68(r=0.51)$ and puppies, $\mathrm{y}=0.061 \mathrm{x}^{2}$ $-1.347 \mathrm{x}+6.11(r=0.69) ;$ left stellate adult dogs, $\mathrm{y}=0.034 \mathrm{x}^{2}-0.569 \mathrm{x}+2.62(r=0.70)$ and puppies, $\mathrm{y}=0.643 \mathrm{x}^{2}-2.749 \mathrm{x}+2.81(r=0.60)$.

no detectable heart rate response to left stellate stimulation, even at very high stimulation frequencies. But there was a significant rise in arterial blood pressure during each stimulation. Blood pressure increased from a mean value of $113 / 58$ to a mean level of $150 / 68$ in those dogs that showed no detectable chronotropic response to left stellate stimulation. Hence, the nerves were viable and the stimuli were effective, even though the stimuli did not alter the cardiac rate.

Adult dogs showed an increase in heart rate with right stellate stimulation that was about double $(P<0.001)$ the response in puppies (Fig. 2; Tables 2 and 3). With left stellate stimulation, the chronotropic responses in the adults were about 3.5 times $(P<$ $0.001)$ those in the puppies.

Comparison of puppy groups. Mean age for Group I puppies (first month of life) was $20.1 \pm 1.8$ days (S.E.M.) with a range of I3-31 days. Mean age for Group II puppies (second month of life) was $46.3+3.0$ days (S.E.M.) with a range of 35-62 days. The ages were significantly different $(P<0.001)$. Each group consisted of ten puppies. After interruption of the autonomic nerves to the heart, the mean heart rates were: Group I, $150+12$ (S.E.M.) and Group II, $128 \pm 7$ (S.E.M.) beats $/ \mathrm{min}$; the difference was not statistically significant. Mean heart rate for Group I puppies (150 \pm 12 ) was higher than that for the adult dogs (130 \pm 6$)$ but this was not statistically significant. Mean heart rate for Group II puppies $(128 \pm 7)$ was similar to that for the adult dogs $(130 \pm 6)$.

Heart rate responses for the older Group II puppies were almost always greater than for the younger Group I puppies; however, these differences were not statistically significant (Tables 1 and 2).

Parasympathetic stimulation. With left vagal stimulation at all frequencies, heart rate responses were greater in the older Group II puppies than in the younger Group I puppies (Table 1).

With right vagal stimulation at lower frequencies, again, the 
Table 1. Comparison of the heart rate responses of adult dogs and puppies to vagal stimulation ${ }^{1}$

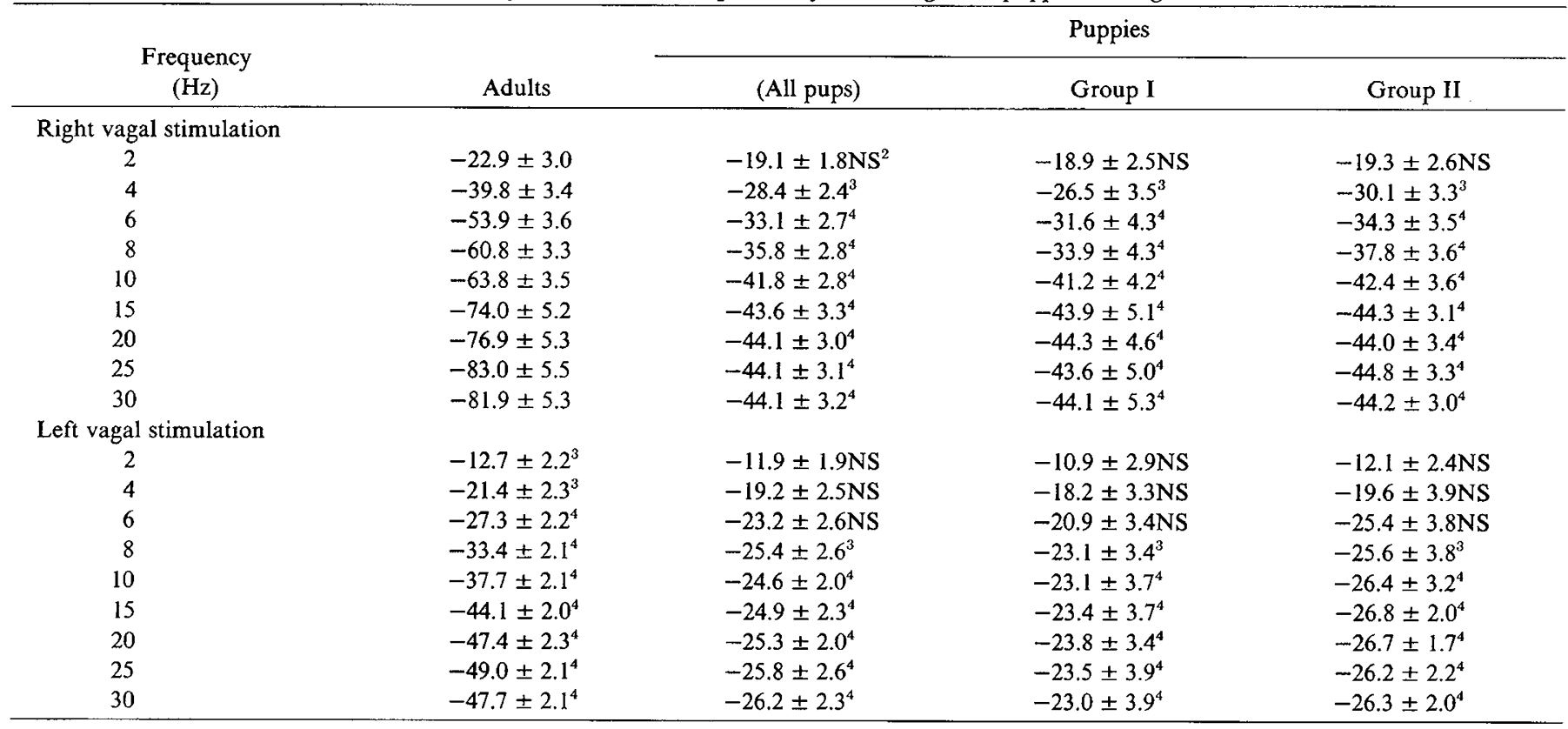

\footnotetext{
${ }^{1}$ Mean \% change in heart rate \pm S.E.M. is listed. Puppies are subdivided into Group I, first month of life and Group II, second month of life. Puppies are compared with the corresponding adult values. In addition, adult left vagus heart rate responses are compared with adult right vagus responses. The $(-)$ indicates the decrease in heart rate occurring with vagal stimulation.

${ }^{2} \mathrm{NS}$, not significant.

${ }^{3} P^{\prime}<0.05$.

${ }^{4} P<0.001$
}

younger Group I puppies had a lesser change in heart rate than the older Group II puppies. At higher stimulation frequencies the heart rate leveled off and responses were similar for both groups (Table 1).

Sympathetic stimulation. With right stellate stimulation at all frequencies, the older Group II puppies had a greater increase in heart rate than the younger Group I puppies (Table 2).

With left stellate stimulation, at maximal frequencies the heart rate increases for Group I puppies were less than one half those for Group II puppies (Table 2).

\section{DISCUSSION}

The chronotropic responses to any given level of neural stimulation were less in puppies than in adult animals. This suggests that the sympathetic and parasympathetic nervous systems are intact and functional in puppies, although they are not fully developed. Significant growth and maturation of both divisions of the autonomic nervous system must occur after birth, and this process must continue past the second month of life.

This functional evaluation of the autonomic nervous control of heart rate in normal, intact puppies is complementary to earlier studies $(9,11)$. Anatomic studies have disclosed that the density of sympathetic nerve fibers in the heart of the newborn is less than that in adult animals $(10,24,28)$. A supersensitivity to exogenous and neural released norepinephrine in newborns has been reported $(3,14,28)$. Histochemical studies have shown a decreased uptake and storage of norepinephrine in cardiac tissue obtained from newborn animals $(6,16,31)$. There is also a relative deficiency of certain intraneuronal enzymes in cardiac tissues obtained from newborn animals (10). Inotropic responses to nerve stimulation in isolated strips of rat ventricular papillary muscles were very low in newborn tissue and increased to near adult values by $3 \mathrm{wk}$ of age (28). This increase in responsiveness was correlated with a progressive increase in sympathetic innervation as detected by fluorescence histochemistry (28). Studies in puppies indicate that functional sympathetic cardiac innervation is incomplete at birth and develops throughout the first $6 \mathrm{wk}$ of life (22).

Previous studies of the parasympathetic nervous system have noted differences between adults and newborns or young animals $(4,5,13,30,46)$. The chronotropic responses to efferent vagal stimulation were less in newborn animals than in adults in most animal species. In newborn kittens, responses to vagal stimulation were undetectable until they were 11 days of age $(5,23)$. Vagotomy caused less increase in heart rate in newborn puppies than in adult dogs $(14,40)$. Newborn rabbits, however, did exhibit a greater bradycardia than did adults to vagal stimulation (41). The density of cholinergic fibers in the sinoatrial node, atrium, A-V node, and ventricle is the same in newborn and adult dogs (10). The parasympathetic response and the acetylcholinesterase content of atrial tissue of newborn rats were less than those of adult rats $(23,31$, $32,45)$. Urthaler et al. (43) have proposed that the target cell response to acetylcholine increases during maturation. This may occur through an increase in the density of muscarinic receptors.

Our study confirms the results of previous investigations, which showed that right-sided autonomic nervous stimulation produced a greater chronotropic response than did left-sided stimulation in adult animals $(29,49)$. We observed a similar difference in newborns. We also found that in some animals (i.e., in $11 \%$ of the adult dogs and in almost half of the puppies), there was no increase in heart rate with left stellate stimulation, even with very intense, high frequency stimulation. There was a significant rise in the mean arterial blood pressure and in the arterial pulse pressure, however. This indicates that the left-sided sympathetic nerves were intact and functional, but that efferent fibers from the left side were not distributed to the sinoatrial node. Randall et al. (34-37) also observed that left sympathetic stimulation sometimes evoked an increased arterial pulse pressure without concomitant changes in heart rate. He ascribed this increase in pulse pressure to an enhancement of ventricular contractility. He concluded that the "left sympathetic directly and richly innervates the sinoatrial node in only a small percentage of animals," although it did evoke a pronounced increase in ventricular contractility. These results are also similar to an earlier study from our group (25) and by others (46).

When the chronotropic responses of puppies in the first and second months after birth were compared, there were no significant differences. When the chronotropic responses of all the 
Table 2. Comparison of the heart rate response of adult dogs and puppies to stellate stimulation

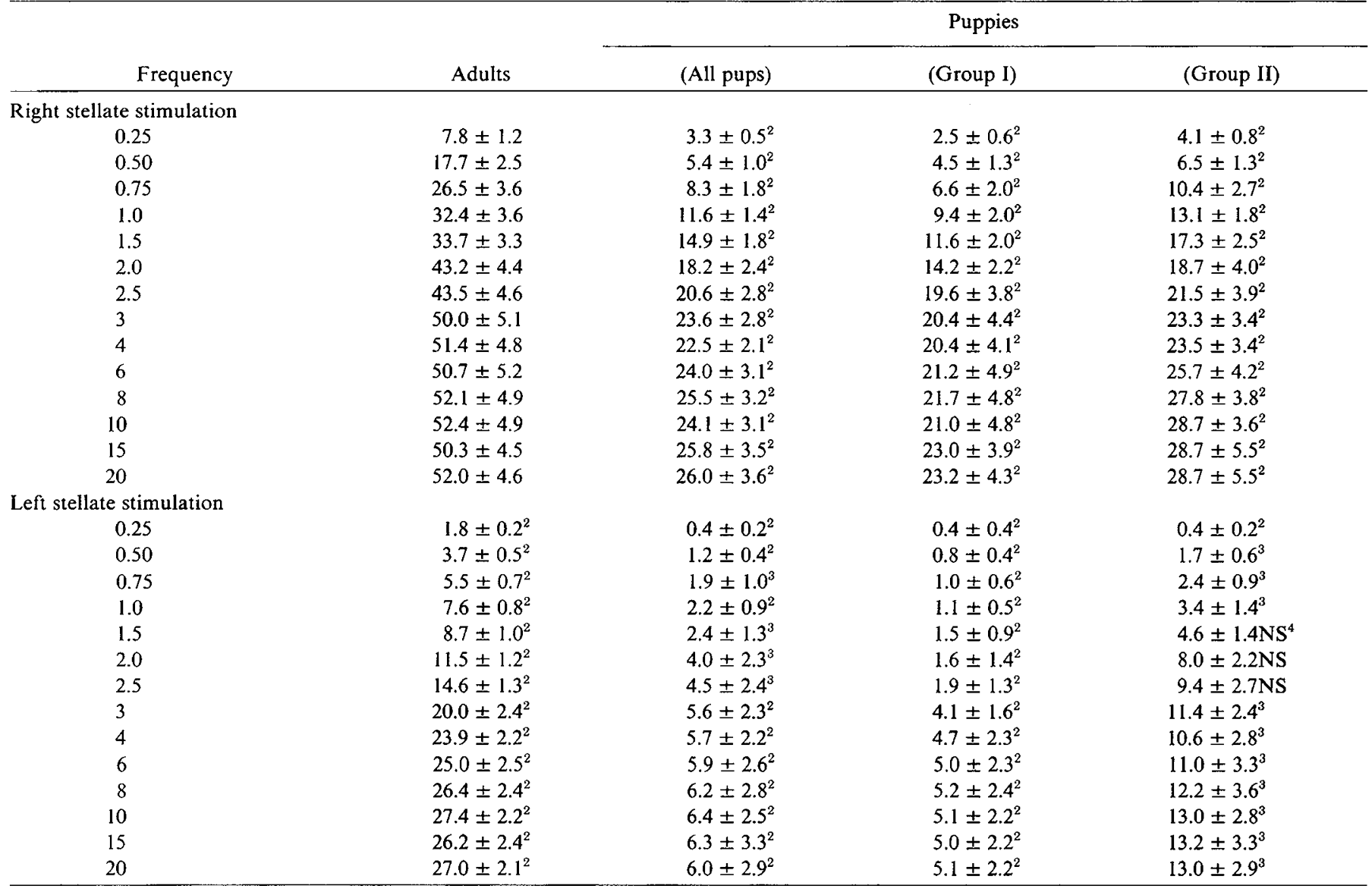

${ }^{1}$ Mean $\%$ change in heart rate \pm S.E.M. is listed. Puppies are subdivided into Group I, first month of life and Group II, second month of life. Puppies are compared with the corresponding adult values. In addition, adult left stellate heart rate responses are compared with adult right stellate heart rate responses.

${ }^{2} P<0.001$

${ }^{3} P<0.05$.

${ }^{4}$ NS, not significant.

Table 3. Analysis of variance of the changes in heart rate in adult dogs and puppies to vagal and stellate stimulation. ${ }^{1}$

\begin{tabular}{lrrr}
\hline \multicolumn{1}{c}{ Source } & $\begin{array}{c}\text { Degrees of free- } \\
\text { dom }\end{array}$ & Mean square & F ratio \\
\hline Vagus & & & \\
Group (G) & 1,014 & 50556 & $37.53^{* *}$ \\
Frequency (F) & 8,112 & 8416 & $126.29^{* *}$ \\
Side (S) & 1,014 & 56898 & $105.64^{* *}$ \\
G X S & 1,014 & 4629 & $11.58^{* *}$ \\
G x F & 8,112 & 1447 & $22.15^{* *}$ \\
S x F & 8,112 & 530 & $12.54^{* *}$ \\
G x S x F & 8,112 & 80 & $2.88^{* *}$ \\
Stellate & & & \\
Group (G) & 1,011 & 53046 & $27.58^{* *}$ \\
Frequency (F) & 13,143 & 3395 & $161.74^{* *}$ \\
Side (S) & 1,011 & 74010 & $49.53^{* *}$ \\
G x S & 1,011 & 10734 & $10.95^{* *}$ \\
G x F & 13,143 & 548 & $9.98^{* *}$ \\
S x F & 13,143 & 470 & $14.60^{* *}$ \\
G x S x F & 13,143 & 57 & $2.49^{* *}$ \\
\hline
\end{tabular}

' The groups $(G)$ are the adult dogs and puppies. The sides (S) are the right and left sides. Stimulation frequency $(F)$ is $0-30 \mathrm{~Hz}$ with vagal stimulation and $0-20 \mathrm{~Hz}$ with stellate stimulation.

${ }^{2} P$ values: significant at $P<0.001=* *$. puppies and adult dogs were compared, the differences were highly significant. This suggests that important functional differences exist between newborn and adult animals and that the maturation process is gradual. A small difference probably does exist between the responses of puppies in the first and second months of life but it was probably too small to be detected in our study. Our findings also indicate that maturation is completed at some time well after the second month of life for both divisions of the autonomic nervous system.

\section{REFERENCES AND NOTES}

1. Anzola, J. and Rushmer, R. F.: Cardiac responses to sympathetic stimulation. Circ. Res., 4: 302 (1956).

2. Assali, N. S., Brinkman, C. R., Woods, J. R., Dandavino, A., and Nuwayhid, B. Development of neurohumoral control of fetal, neonatal, and adult cardiovascular functions. Am. J. Obst. Gynecol., 129: 748 (1977).

3. Boatman, D. and Brody, M.: Cardiac responses to adrenergic stimulation in the newborn dog. Arch. Int. Pharmacodyn. Ther., 170: 1 (1967).

4. Brus, R. and Jacobowitz, D.: Influence of norepinephrine, tyramine, and acetylcholine on isolated perfused hearts of immature and adult rabbits. Arch. Int. Pharmacodyn. Ther., 200: 266 (1972).

6. Clark, G.: The development of blood pressure reflexes. J. Physiol. (Lond), 83: 229 (1935).

6. Davies, P., Horrobin, D. F., Manku, M. S., Nassar, B. A. and Tynam, M.: Postnatal development of sympathetic innervation in the rabbit heart (abstr). J. Physiol. (London), 224: 69 (1975).

7. Dawes, G. S., Handler, J. J. and Mott, J. C.: Some cardiovascular responses in fetal, newborn and adult rabbits. J. Physiol. (London), 139: 123 (1957). 
8. Downing, S. E., Lee, J. C., and Taylor, J.: Cardiac function and metabolism during cholinergic stimulation in the newborn lamb. Am. J. Physiol., 233: H451 (1977).

9. Friedman, W. F.: Neuropharmacologic studies of perinatal myocardium. Cardiovasc. Clin., 222: 285 (1972).

10. Friedman, W. F.: The intrinsic physiologic properties of the developing heart. Prog. Cardiovasc. Dis., 15(1): 87 (1972).

11. Friedman, W. F., Pool, P. E., Jacobowitz, D., Seagren, S. C., and Braunwald, E.: Sympathetic innervation of the developing rabbit heart. Biochemical and histochemical comparisons of fetal, neonatal, and adult myocardium. Circ. Res., 23: 25 (1968).

12. Galper, J., Klein, W., and Catterall, W.: Muscarinic acetylcholine receptors in developing chick heart. J. Biol. Chem., 252: 8692 (1977).

13. Gauthier, P., Nadeau, R., and de Champlain, J.: The development of sympathetic innervation and the functional state of the cardiovascular system in newborn dogs. Can. J. Physiol., 53: 763 (1975).

14. Geis, W. P., Tatooles, C. J., Priola, D. V. and Friedman, W. F.: Factors influencing neurohumoral control of the heart in the newborn dog. Am. J. Physiol., 228(6): 1685 (1975).

15. Gifford, P., Ouyang, G., Franke, F., Clarke, A., and Ertel, R.: Choline acetyltransferase (CAT) in hearts of developing embryos. Pharmacologist, 15: (abstract) 198 (1973)

16. Glowinski, J., Axelrod, J., Kopin, J. J., and Wurtman, R. J.: Physiological deposition of $\mathrm{H}^{3}$ norepinephrine in the developing rat. J. Pharmacol. Exp. Ther., 146: 48 (1964).

17. Gootman, P. M., Buckley, N. M., and Gootman, N.: Postnatal maturation of neural control of the circulation. Perinatal. Med., 3: 1 (1979).

18. Hall, E. K.: Acetylcholine and epinephrine effects on the embryonic rat heart. J. Cell Comp. Physiol., 49: 187 (1957).

19. Hicks, C. R.: Factorial experiments. Fixed, random and mixed models. In: Fundamental concepts in the Design of Experiments. pp. 86-107 and 173-187. (Holt Rhinehart and Winston Inc, New York, 1973.)

20. Hutchinson, E., Percival, C., and Young, I.: Development of cardiovascular responses in the kitten. Q. J. Exp. Physiol., 47: 201 (1962).

21. Jennrich, R. and Sampson, P.: Analysis of variance and covariance. In: EMDP Biomedical Computer Programs P-series 1979, Dixon, W. J. and Brown, M. B., Ed. pp. 540-580. (University of California Press, Berkeley, Calif, 1979.)

22. Kralios, F. and Millar, K.: Functional development of cardiac sympathetic nerves in newborn dogs: evidence for asymmetrical development. Cardiovasc. Res., 12: 547 (1978).

23. Kuntscherova, J. and Vik, J.: Postnatal changes in the amount of acetylcholine in the atrial tissue of the albino rat heart. Physiol. Bohem., 28: 569 (1979).

24. Lebowitz, E. A., Novick, J. S., and Fudolph, A. M.: Development of myocardial sympathetic innervation in the fetal lamb. Pediatr. Res., 6: 887 (1972).

25. Levy, M. N. and Blattberg, B.: Correlation of the mechanical responses of the heart with the norepinephrine overflow during cardiac sympathetic neural stimulation in the dog. Cardiovasc. Res., 11(6): 481 (1977).

26. Levy, M. N., Ng, M. L., and Zieske, H.: Functional distribution of the peripheral cardiac sympathetic pathways. Circ. Res., 19: 650 (1966).

27. Loffelholz, K. and Pappano, A.: Increased sensitivity of sinoatrial pacemaker to acetylcholine and to catecholamines at the onset of autonomic neuroeffector transmission in chick embryo heart. J. Pharmacol. Exp. Ther., 191: 479 (1974).

28. MacKenzie, E. and Standem, N. B.: The postnatal development of adrenoreceptor responses in isolated papillary muscles from rat. Pflugers Arch., 383: 185 (1980).

29. Marvin, W. J., Hermsmeyer, K., McDonald, R. I., Roskoski, L., and Roskoski, R.: Ontogenesis of cholinergic innervation in the rat heart. Circ. Res., 46: 690
(1980).

30. Marvin, W. J., Roskoski, R. and Hermsmeyer, K.: Ontogenesis of autonomic innervation in mammalian myocardium. Pediatr. Res., 2: 395 (1977).

31. Merkin, B. L.: Ontogenesis of the adrenergic nervous system: functional and pharmacologic implications. Fed. Proc., 31(1): 65 (1972).

32. Navarathnam, V.: The ontogenesis of cholinesterase activity within the heart and cardiac ganglia in man, rat, rabbit, and guinea pig. J. Anat., 99: 459 (1965).

33. Pappano, A. and Loffelholz, K.: Ontogenesis of adrenergic and neuroeffector transmission in chick embryo heart. J. Pharmacol. Exp. Ther., 191: 468 (1974)

34. Randall, W. C., McNally, H., Cown, J., Caliguiri, L., and Rohse, W.: Functional analysis of the cardioaugmentor and cardioaccelerator pathways in the dog. Am. J. Physiol., 191: 231 (1957)

35. Randall, W. C., Priola, D., Pace, J., and Wechsler, J.: Ventricular augmentor fibers in the cervical vagosympathetic trunk. Proc. Soc. Exp. Biol. Med., 124 1254 (1967).

36. Randall, W. C., Priola, D. V., and Ulmer, R. H.: A functional study of distribution of cardiac sympathetic nerves. Am. J. Physiol., 205(6): 1227 (1963).

37. Randall, W. C., Wechsler, J., Pace, J., and Sventivanyi, M.: Alterations in myocardial contractility during stimulation of the cardiac nerves. Am. J. Physiol., 214(5): 1205 (1968).

38. Sokal, R. F. and Rohlf, F. T.: Multivay analysis of variance; and regression. In: Biometry: The Principles and Practice of Statistics in Biological Research. pp. 343-364 and 404-493. (W. H. Freedman and Co., 1969.)

39. Steel, R. and Torrie, J.: Factorial Experiments. Linear Regression Equations. In: Principles and Procedures of Statistics with Special Reference to the Biological Sciences. pp. 194-231 and 161-182. (McGraw-Hill Book Company, Inc., New York, 1960.)

40. Todo, N., Fu, W., and Osumi, Y.: Age-dependence of chronotropic response to noradrenaline, acetylcholine and transmural stimulation in isolated rabbit atria. Jap. J. Pharmacol., 26: 359 (1976).

41. Truex, R., Scott, K., Long, D. and Smith, O.: Effect of vagus nerves on heart rate of young dogs: an anatomic-physiologic study. Anat. Rec., 228: 685 (1955).

42. Tynan, M., Davies, P. and Sheridan, D.: Postnatal maturation of noradrenaline uptake and release in cat papillary muscles. Cardiovasc. Res., 11: 206 (Abstract) (1977).

43. Urthaler, F., Walker, A., and James, T.: Changing negative inotropic effect of acetylcholine in maturing canine cardiac muscle. Am. J. Physiol., 238: H1 (1980).

44. Versprille, A. and Wise, M. E.: Quantitative effect of vagal stimulation on heart interval in newborn and older rabbits. Pflugers Arch., 325: 61 (1971).

45. Vik, J.: Postnatal development of postganglionic parasympathetic neurons in the heart of the albino rat. Physiol. Bohem., 28: 561 (1979).

46. Vik, J. and Vincenzi, F.: Functional autonomic innervation of mammalian cardiac pacemaker during perinatal period. Biol. Neonate, 31: 19 (1977).

47. Wildenthal, K.: Maturation of responsiveness to cardioactive drugs. J. Clin. Invest., 52: 2250 (1973)

48. Woods, J. R. Jr., Dandavino, A., Brinkman, C. R. III, and Nuwayhid, B.: Cardiac output changes during neonatal growth. Am. J. Physiol., 234: H412 (1978).

49. Yanowitz, F., Preston, J. B., and Abildskov, J. A.: Functional distribution of right and left stellate innervation to the ventricles. Circ. Res., 18: 416 (1966).

50. Requests for reprints should be addressed to: Dr. Sharon Mace, Division of Investigative Medicine, The Mt. Sinai Medical Center, 1800 East 105th Street, Cleveland, Ohio 44106.

51. This work was supported by the U.S. Public Health Grant HL 15758. Sharon Mace was a postdoctoral research fellow of the Haas Trust Fund.

52. Received for publication November 5, 1981 .

53. Accepted for publication October 1, 1982. 